\title{
Hazelnut (Corylus avellana L.) kernels as a source of antioxidants and their potential in relation to other nuts
}

\author{
Teresa Delgado, Ricardo Malheiro, José Alberto Pereira, Elsa Ramalhosa* \\ CIMO, Escola Superior Agrária, Instituto Politécnico de Bragança, Campus de Santa Apolónia, Apartado 1172, 5301-855 Bragança, Portugal
}

\section{A R T I C L E I N F O}

\section{Article history:}

Received 7 June 2010

Received in revised form 20 July 2010

Accepted 22 July 2010

\section{Keywords:}

Hazelnut kernels

Antioxidant activity

Total phenols content

Extraction methods

\begin{abstract}
A B S T R A C T
The present work evaluates the potential of hazelnut kernels as a source of antioxidants to be incorporated into new products. First, the effects of extraction conditions on the isolation of hazelnut kernels' total phenols and antioxidants were evaluated. Six conditions, involving different solvents (water, methanol and aqueous acetone) and contact times, were studied. The highest total phenol contents were obtained with boiling water for $30 \mathrm{~min}, 44.3 \pm 7.7 \mathrm{mg} \mathrm{GAE} / \mathrm{g}_{\text {extract}}$, and $80 \%(\mathrm{v} / \mathrm{v})$ aqueous acetone solution for

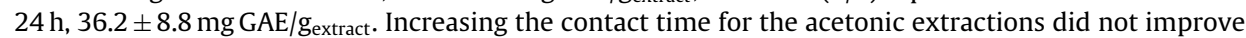
the total phenols content. Regarding antioxidant activity, the highest DPPH-scavenging effect value was obtained with $80 \%(\mathrm{v} / \mathrm{v})$ aqueous acetone for $24 \mathrm{~h}$ with an effective concentration $\left(\mathrm{EC}_{50}\right)$ equal to $1.12 \pm 0.07 \mathrm{mg} / \mathrm{mL}$. When other nuts - walnuts, almonds, pine nuts and peanuts - were extracted under this condition, only walnut extract exhibited higher phenol content $\left(268 \pm 32 \mathrm{mg} \mathrm{GAE} / \mathrm{g}_{\text {extract }}\right)$, antioxidant activity as measured by reducing power $\left(\mathrm{EC}_{50}=0.091 \pm 0.015 \mathrm{mg} / \mathrm{mL}\right)$ and free radical scavenging capacity (DPPH assay) $\left(\mathrm{EC}_{50}=0.060 \pm 0.010 \mathrm{mg} / \mathrm{mL}\right.$ ) than hazelnut extract. The present work demonstrates that some nuts might be a natural source of bioactive compounds that can be incorporated into new health-related products or be substitutes of synthetic compounds of questionable safety, promoting human health and reducing disease risks.
\end{abstract}

(C) 2010 Elsevier B.V. All rights reserved.

\section{Introduction}

Hazelnuts (Corylus avellana L.) are consumed all over the world in dairy, bakery, candy and chocolate products. Besides being highly nutritious, hazelnuts have other properties that might be useful in the development of products other than foods, for example, cosmetics and pharmaceuticals.

Hazelnuts have a high fat content (Kornsteiner et al., 2006); monounsaturated (MUFAs) and polyunsaturated fatty acids (PUFAs) are the major compounds in hazelnut fatty acids (Parcerisa et al., 1998; Köksal et al., 2006; Venkatachalam and Sathe, 2006; Oliveira et al., 2008). The presence of these compounds might bring health benefits related to blood serum lipid profile, protecting low density lipoprotein (LDL) from oxidation and decreasing plasma oxidized LDL levels (Orem et al., 2008). Durak et al. (1999) verified that after hazelnut supplementation, the malondialdehyde (MDA) levels of plasma samples were significantly lower and the antioxidant potential (AOP) values higher, indicating that peroxidation reactions were, to a great extent, prevented by the antioxidant constituents of hazelnuts (Durak et al., 1999). Because oxidative stress is now thought to contribute to all inflammatory diseases,

\footnotetext{
* Corresponding author. Tel.: +351 273303 308; fax: +351 273325405

E-mail address: elsa@ipb.pt (E. Ramalhosa).
}

ischemic diseases, cancer, hemochromatosis, acquired immunodeficiency syndrome (AIDS), emphysema, organ transplantation, gastric ulcers, hypertension and preeclampsia, neurological diseases, alcoholism, smoking-related diseases and others, it is of prime importance to find natural products and identify plants with antioxidant potential that can reduce these phenomena. Antioxidant compounds are essential in the development of products linked to health and well being, particularly pharmaceuticals and cosmetics.

Studies of nuts such as walnuts, pecans, chestnuts and pistachios indicate that they have great potential to be good sources of antioxidants (Blomhoff et al., 2006; Kornsteiner et al., 2006). Hazelnuts are not an exception. Numerous studies have reported the antioxidant activities of extracts obtained from hazelnut kernels (Alasalvar et al., 2006; Shahidi et al., 2007; Oliveira et al., 2008), oils (Arranz et al., 2008; Miraliakbari and Shahidi, 2008) and by-products (Shahidi et al., 2007; Contini et al., 2008; Alasalvar et al., 2009). However, with a few exceptions (Alasalvar et al., 2006; Contini et al., 2008; Alasalvar et al., 2009), most of these studies involved aqueous solutions of ethanol, methanol or acetone extractions with a fixed contact time. Because the solvents used in the extractions, as well as the experimental conditions, might affect the extraction yield, total phenols content and antioxidant activity, studies that compare the effects of different extraction conditions and solvents on the quality and quantity 
of phenol contents and antioxidant activity are of great importance.

Therefore, this study (I) Evaluated the effects of different extraction conditions (solvent type and contact time) on the antioxidant activities of hazelnut kernels; and (II) Compared the total phenol contents and antioxidant capacities of hazelnut kernels with those of other nut species, including walnuts (Juglans regia L.), almonds (Prunus dulcis L.), pine nuts (Pinus pinea L.) and peanuts (Arachis hypogaea $\mathrm{L}$.). Thus, this study identified the nut species with the highest phenol contents and/or antioxidant activities, thereby identifying those with the highest potential for use in new products to promote human well being (i.e., cosmetics) and reduce disease risk (i.e., medicines).

\section{Experimental}

\subsection{Plant samples}

Hazelnut (C. avellana L.) cultivars, specifically Daviana, Fertille de Coutard and Merveille de Bollwiller, were collected in early September 2008 in Bragança, northeastern Portugal. Approximately $2-5 \mathrm{~kg}$ of fruits from each cultivar were handpicked from the ground and taken to the laboratory, where they were dried in a convection oven (Memmert Schwabach 854,1994 ) at $30^{\circ} \mathrm{C}$, in the dark, for five days. Afterward, the fruits were put in plastic bags and frozen to $-20^{\circ} \mathrm{C}$ until they could be analyzed. The hazelnuts were then thawed, manually cracked, the hard shells removed, and the hazelnut kernels (with skin) were chopped in a mill (Model A327R1, Moulinex, Spain) ( $\leq 20$ mesh) immediately before the analyses.

Several dry nuts, specifically walnut (J. regia L.), almond ( $P$. dulcis L.), pine nut (P. pinea L.) and peanut (A. hypogaea L.) seeds, were purchased in a local market and subjected to the extraction conditions (solvent and contact time) that had resulted in the highest total phenol contents and antioxidant activity for hazelnuts. All nuts were already unshelled and without skin except the walnuts, which only had their exterior husks removed. All nuts were chopped in a mill (model A327R1, Moulinex, Spain) immediately before using.

\subsection{Chemicals and reagents}

Gallic acid, 2,2-diphenyl-1-picrylhydrazyl (DPPH) free radical and ferric chloride $\left[\mathrm{FeCl}_{3} \cdot 6 \mathrm{H}_{2} \mathrm{O}\right]$ were of analytical grades and supplied by Sigma-Aldrich (St. Louis, MO, USA). Folin and Ciocalteu's phenol reagent, sodium carbonate and trichloroacetic acid (TCA) were obtained from Fluka (Steinheim, Switzerland), Panreac (Barcelona, Spain) and Merck (Darmstadt, Germany), respectively. Phosphate buffer ( $\mathrm{pH}$ 6.6) was prepared from sodium dihydrogen phosphate $\left(\mathrm{NaH}_{2} \mathrm{PO}_{4} \cdot 2 \mathrm{H}_{2} \mathrm{O}\right)$ and disodium hydrogen phosphate $\left(\mathrm{Na}_{2} \mathrm{HPO}_{4} \cdot 2 \mathrm{H}_{2} \mathrm{O}\right)$, purchased from Merck (Darmstadt, Germany) and Panreac (Barcelona, Spain), respectively. Methanol and acetone used in the extractions were of HPLC grades and were obtained from Sigma-Aldrich (St. Louis, MO, USA) and Pronalab (Lisbon, Portugal). Water was treated in a Milli-Q water purification system (TGI Pure Water Systems, USA).

\subsection{Extraction conditions}

First, several extraction conditions were evaluated to determine their effects on total phenol extraction and the antioxidant activity of hazelnut kernels. Solvent and time of contact were studied. Samples of hazelnuts (a quantitative mixture of the three $C$. avellana cultivars referred to above) were used for these studies. The extraction conditions evaluated were: (1) $5 \mathrm{~g}$ of chopped hazelnuts was extracted with $250 \mathrm{~mL}$ of boiling water for $45 \mathrm{~min}$, as described in Sousa et al. (2008); (2) $5 \mathrm{~g}$ of chopped hazelnuts was stirred with $100 \mathrm{~mL}$ of methanol at room temperature at $150 \mathrm{rpm}$ for $24 \mathrm{~h}$ and filtered through Whatman no. 4 paper (Sousa et al., 2008); (3) $5 \mathrm{~g}$ of chopped hazelnuts was processed as described in Condition 2 , but with an additional extraction with $100 \mathrm{~mL}$ of methanol for $24 \mathrm{~h}$, with the supernatants combined. This assay was reported as $24+24 \mathrm{~h}$; (4-6) $6 \mathrm{~g}$ of chopped hazelnuts was extracted with $60 \mathrm{~mL}$ of $80 \%(v / v)$ of aqueous acetone, as described in Contini et al. (2008),

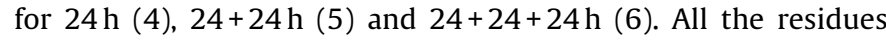
were re-extracted. In the corresponding assays, the aqueous (1) and acetonic supernatants (4-6) were frozen and lyophilized. The methanolic extracts ( 2 and 3 ) were evaporated at $40^{\circ} \mathrm{C}$ until dry. All the extracts were redissolved in the corresponding solvent at a concentration of $50 \mathrm{mg} / \mathrm{mL}$ and analyzed for their total phenol contents and antioxidant activities.

Because the extracts produced with $80 \%(\mathrm{v} / \mathrm{v})$ aqueous acetone for $24 \mathrm{~h}$ showed the highest antioxidant activity (see Section 3 ), this extraction condition was applied to the other nuts.

\subsection{Determination of total phenol contents}

Total phenol contents in the extracts were estimated by a colorimetric assay based on the procedure described by Singleton and Rossi (1965) and used in other research studies (Alasalvar et al., 2006; Klimczack et al., 2007; Oliveira et al., 2008) with some modifications. Briefly, $1 \mathrm{~mL}$ of sample was mixed with $1 \mathrm{~mL}$ of Folin-Ciocalteu's phenol reagent. After $3 \mathrm{~min}, 1 \mathrm{~mL}$ of saturated sodium carbonate solution was added to the mixture and adjusted to $10 \mathrm{~mL}$ with distilled water. The reaction was kept in the dark for $90 \mathrm{~min}$, after which the absorbance was read at $725 \mathrm{~nm}$ (Analytik Jena 200-2004 Spectrophotometer). A blank devoid of any extract was used for background subtraction. Total phenol contents of each extract were determined from standard curves $(0.01-0.8 \mathrm{mM}$; correlation coefficients $(r)>0.99$ ) prepared daily, using gallic acid as a standard. Results were expressed as milligrams of gallic acid equivalents (GAEs) per gram of extract.

\subsection{Antioxidant activity}

\subsubsection{Free radical scavenging (DPPH) assay}

The capacity to scavenge the 2,2-diphenyl-1-picrylhydrazyl (DPPH) free radical was monitored according to the method described by Oliveira et al. (2008). Several concentrations of the hazelnut extracts $(0.3 \mathrm{~mL})$ were mixed with $2.7 \mathrm{~mL}$ of methanolic solution containing DPPH radicals $\left(6 \times 10^{-5} \mathrm{~mol} / \mathrm{L}\right)$. The mixture was shaken vigorously and left to stand in the dark until stable absorption values were obtained at $517 \mathrm{~nm}$. DPPH-scavenging effect was calculated as percentage of DPPH discoloration using the equation: \% Scavenging effect $=\left[\left(A_{\mathrm{DPPH}}-A_{\mathrm{S}}\right) / A_{\mathrm{DPPH}}\right] \times 100$, where $A_{\mathrm{S}}$ was the absorbance of the solution in which the sample extract had been added at a particular level and $A_{\mathrm{DPPH}}$ was the absorbance of the DPPH solution. The extract concentrations providing $50 \%$ inhibition $\left(\mathrm{EC}_{50}\right)$ were calculated from the graphs of scavenging effect percentages against extract concentrations.

\subsubsection{Reducing-power assay}

Reducing powers in the obtained extracts were determined by the procedure described by Berker et al. (2007) with some modifications. Briefly, various concentrations of the sample extracts $(1 \mathrm{~mL})$ were mixed with $2.5 \mathrm{~mL}$ of $0.2 \mathrm{M}$ phosphate buffer $(\mathrm{pH}$ 6.6) and $2.5 \mathrm{~mL}$ of $1 \%(\mathrm{w} / \mathrm{v})$ solution of $\mathrm{K}_{3} \mathrm{Fe}(\mathrm{CN})_{6}$; the mixtures were incubated at $50^{\circ} \mathrm{C}$ on a water bath for $20 \mathrm{~min}$. The incubated mixtures were left to cool to room temperature and $2.5 \mathrm{~mL}$ of $10 \%(\mathrm{w} / \mathrm{v})$ TCA solution was added. The solution was mixed thoroughly, an aliquot of $2.5 \mathrm{~mL}$ was withdrawn and $0.5 \mathrm{~mL}$ of $0.1 \%(\mathrm{w} / \mathrm{v})$ $\mathrm{FeCl}_{3} \cdot 6 \mathrm{H}_{2} \mathrm{O}$ solution was added. The absorbance of the resulting Prussian blue solution at $700 \mathrm{~nm}\left(A_{700}\right)$ was measured after $2 \mathrm{~min}$ against a reagent blank. The extract concentration providing 0.5 of 


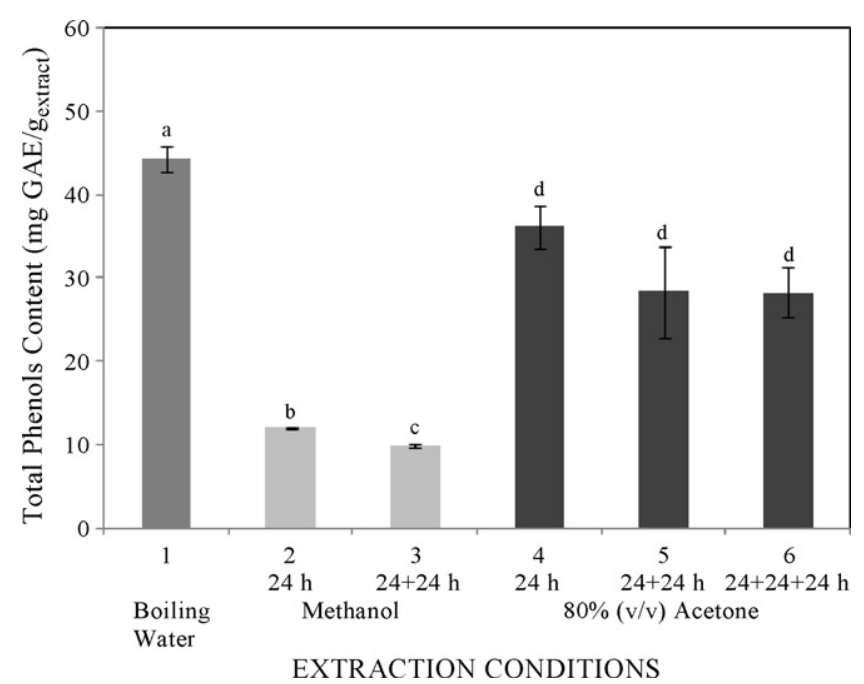

Fig. 1. Total phenol contents of hazelnut kernels extracts obtained by different extraction conditions: (1) boiling water for $45 \mathrm{~min}$; ( 2 and 3) methanol for 24 and $24+24 \mathrm{~h}$, respectively; (4-6) $80 \%(\mathrm{v} / \mathrm{v}$ ) aqueous acetone for $24,24+24$ and $24+24+24 \mathrm{~h}$, respectively. Results are expressed as $\mathrm{mg} \mathrm{GAE} / \mathrm{g}_{\text {extract }} \pm \mathrm{SD}(n=6)$.

absorbance $\left(\mathrm{EC}_{50}\right)$ was calculated from the graph of $A_{700}$ against the extract concentration.

\subsection{Statistical analysis}

All extractions were carried out in triplicate, being all further measurements and analyses carried out in duplicate. The results were analyzed statistically using the SAS v.9.1.3 program. Depending on the existence of normality and homogeneity of the data, one-way analyze of variance (ANOVA), ANOVA-Welch or Kruskal-Wallis Tests were performed in order to compare extraction conditions and nuts.

\section{Results and discussion}

\subsection{Influence of the experimental conditions on the extraction of total phenols}

The influences of different solvents - water, methanol and $80 \%$ $(\mathrm{v} / \mathrm{v})$ aqueous acetone - and contact times on the extraction of total phenols from hazelnut kernels, and on the antioxidative capacity of the obtained extracts, were studied. Water, methanol and $80 \%(\mathrm{v} / \mathrm{v})$ aqueous acetone were chosen as solvents because they were used in many similar studies and represent different polarities and selectivity parameters. These factors were expected to play an important role in extracting total phenols from hazelnut kernels.

The results obtained show that the extraction of total phenols depended $(p<0.05)$ on the solvent and time of contact used (Fig. 1). It is worth noting that the optimal conditions for total phenol extraction should extract the highest quantity of these compounds and the lowest quantity of foreign substances. In addition, the best conditions should produce the highest ratio of total extractable phenols to total extract. In the present work, the first conditions to be tested were boiling water for $45 \mathrm{~min}$ and methanol and acetone $80 \%(\mathrm{v} / \mathrm{v})$ at room temperature for $24 \mathrm{~h}$. An analysis of the total phenol contents of the corresponding extracts revealed that the highest values were obtained with water, even when a shorter extraction time was used. In response, the extraction times for the organic solvents were increased; however, water always revealed the best extracting capacity, with total phenol concentrations equal to $44.3 \pm 7.7 \mathrm{mg} \mathrm{GAE} / \mathrm{g}_{\text {extract }}$. With methanol, the total phenol contents decreased significantly when the time of con- tact increased $(p<0.05)$, and extractions with methanol always had the lowest concentrations, 9.82-12.1 mg GAE/gextract. In contrast, the three acetonic extractions (4: $36.2 \pm 8.8 ; 5: 28.4 \pm 0.24$; 6: $28.2 \pm 6.5 \mathrm{mg} \mathrm{GAE} / \mathrm{g}_{\text {extract, }}$ respectively), showed no significant differences in total phenol contents $(p>0.05)$. Therefore, extraction with $80 \%(\mathrm{v} / \mathrm{v})$ aqueous acetone at room temperature for $24 \mathrm{~h}$ appeared to be sufficient for extracting total phenols from hazelnut kernels, and longer extractions showed no additional benefit.

Based on these results, solvent power and extraction time may be put in the following order of total phenols extraction: boiling water $(45 \mathrm{~min})>80 \%(\mathrm{v} / \mathrm{v})$ aqueous acetone $(24,24+24$, $24+24+24 \mathrm{~h})>$ methanol $(24 \mathrm{~h})>$ methanol $(24+24 \mathrm{~h})$. The significant decrease observed with methanol for $24+24 \mathrm{~h}$ may have been caused by its increased capacity to solubilize a higher quantity of foreign substances, leading to the lowest phenol content among the extracts. Similar results were reported by Contini et al. (2008), who analyzed several types of hazelnut by-products. They extracted hazelnut shell waste, the skin waste of whole roasted hazelnuts and the skin waste of chopped hazelnuts with $80 \%(\mathrm{v} / \mathrm{v})$ aqueous methanol, ethanol or acetone, and found that the methanolic solvent was undoubtedly the least suitable. Moreover, Alasalvar et al. (2006) extracted phenolic compounds from hazelnut kernels with $80 \%(\mathrm{v} / \mathrm{v})$ ethanol and $80 \%(\mathrm{v} / \mathrm{v})$ acetone at $50^{\circ} \mathrm{C}$ for $30 \mathrm{~min}$ and verified that the ethanol extract had a lower total phenol content than the $80 \%$ acetone extract. In fact, aqueous acetone is considered a good solvent for phenolics, especially tannin compounds (Makkar, 2000), which may account for the majority of the phenolic substances in the hazelnut extracts, representing almost $60-65 \%$ of the total phenols (Contini et al., 2008).

Our results also underscore the importance of choosing the most suitable solvent for extracting the phenols in hazelnut kernels. In fact, these data indicate that solvents with higher polarity, such as water $\left(P_{\text {water }}^{\prime}=10.2\right.$ versus 5.1 of methanol and acetone), extracted these compounds best, followed by solvents with high tendencies to participate in dipolar interactions. Thus, acetone has a higher $x_{n}$ selectivity parameter $(0.42)$ than methanol $\left(x_{n}=0.31\right)$. In contrast, solvents with higher tendencies to participate in hydrogen bonding as acceptors (with higher $x_{e}$ selectivity parameter), such as methanol $\left(x_{e}=0.48\right)$, are less efficient in extracting the phenols from hazelnut kernels.

\subsection{Effect of extraction conditions on antioxidant activity}

Several analytical methods have been developed to determine the in vitro antioxidant activity of plants and their derivatives. Different substrates, reaction conditions and kinetic and quantitation methods have been used, making it difficult to compare the obtained results. In this work, the DPPH assay was used to characterize the antioxidant capacity hazelnut kernel extracts because it is one of the most accurate, sensitive and widely used methods for characterizing the antioxidant capacity food product extracts. Antioxidant molecules can quench DPPH free radicals and convert them to a colorless/bleached product (i.e. 2,2-diphenyl1-hydrazine, or a substituted analogous hydrazine), resulting in a decrease in absorbance at $517 \mathrm{~nm}$ (Sousa et al., 2008).

The scavenging effect of the hazelnut kernels was expressed as $\mathrm{EC}_{50}$ values, as reported in Table $1 . \mathrm{EC}_{50}$ values represent the amount of extract required to scavenge $50 \%$ of DPPH radicals. Thus, higher $\mathrm{EC}_{50}$ values mean lower antioxidant activity. All hazelnut extracts showed scavenging activity against DPPH radicals that increased when the extract concentration increased (Fig. 2). The extracts obtained with acetone were the most active (Table 1), as the lowest values were obtained with this solvent $\left(\mathrm{EC}_{50}: 1.12-1.53 \mathrm{mg} / \mathrm{mL}\right.$ ). This fact is probably related to the higher concentration of antioxidants (mainly tocopherols) in the fat fraction (Oliveira et al., 2008) and/or tannins, particularly condensed 
Table 1

Radical scavenging ability (DPPH assay) of hazelnut extracts, expressed as $\mathrm{EC}_{50}$ values $(\mathrm{mg} / \mathrm{mL})$, obtained with different extraction conditions. ${ }^{\text {a }}$

\begin{tabular}{ll}
\hline Extraction method & $\mathrm{EC}_{50}(\mathrm{mg} / \mathrm{mL})$ \\
\hline Water & $4.02 \pm 0.74 \mathrm{a}$ \\
Methanol $24 \mathrm{~h}$ & $12.8 \pm 1.4 \mathrm{~b}$ \\
Methanol $24+24 \mathrm{~h}$ & $12.4 \pm 2.4 \mathrm{~b}$ \\
$80 \%$ acetone $24 \mathrm{~h}$ & $1.12 \pm 0.07 \mathrm{c}$ \\
$80 \%$ acetone $24+24 \mathrm{~h}$ & $1.53 \pm 0.05 \mathrm{~d}$ \\
$80 \%$ acetone $24+24+24 \mathrm{~h}$ & $1.32 \pm 0.19 \mathrm{c}, \mathrm{d}$ \\
\hline
\end{tabular}

Values with different letters are significantly different $(p<0.05)$.

a Mean $\pm \operatorname{SD}(n=6)$.

tannins (Alasalvar et al., 2006, 2009), resulting from this solvent. Moreover, no significant decreases in $\mathrm{EC}_{50}$ values $(p>0.05)$ were observed when the extraction time increased from 24 to $24+24+24 h$.

As observed with total phenols, the methanolic extracts showed the lowest antiradical ability, represented by the highest $\mathrm{EC}_{50}$ values: $12.4-12.8 \mathrm{mg} / \mathrm{mL}$ for $24+24$ and $24 \mathrm{~h}$, respectively. Alasalvar et al. (2006) also examined the DPPH radical scavenging capacity of ethanolic and acetonic extracts of hazelnut kernels and found similar results; namely, that ethanol was a less efficient solvent than acetone. Water, the solvent that yielded the highest phenolic extract concentration, did not show the highest DPPH-scavenging activity. Thus, the phenolic compounds extracted with water did not exhibit higher antiradical ability.
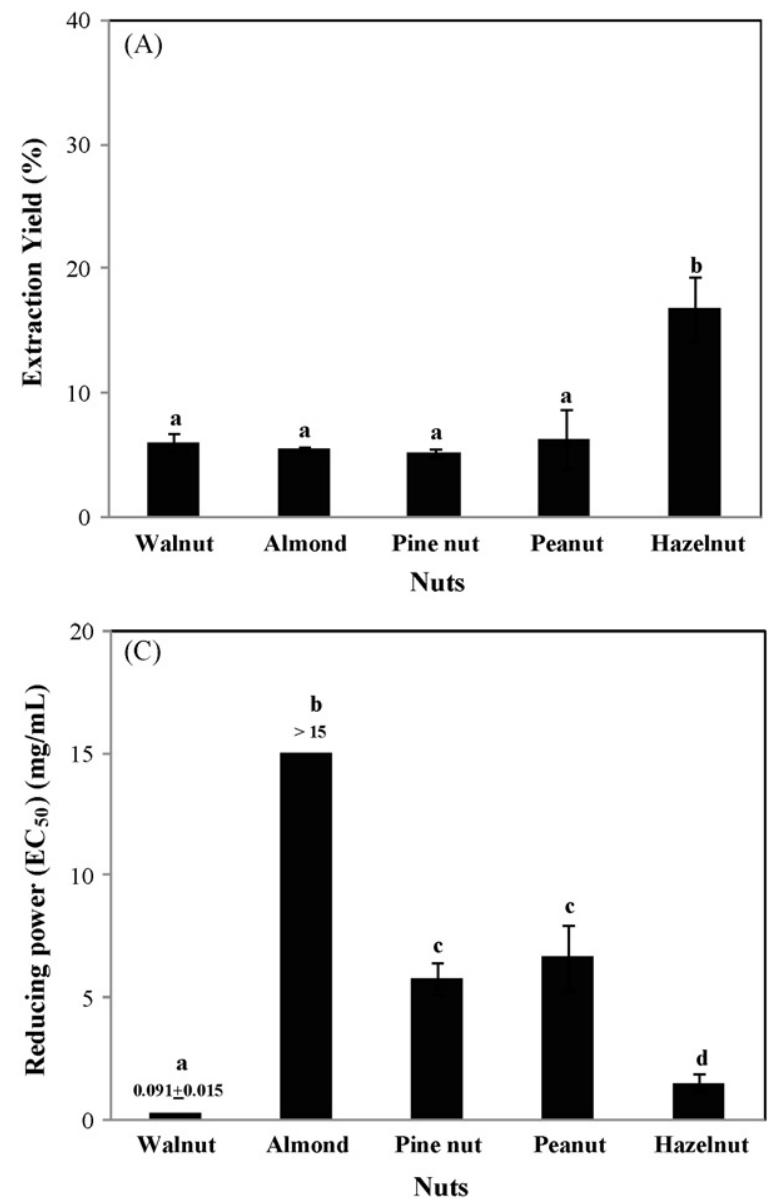

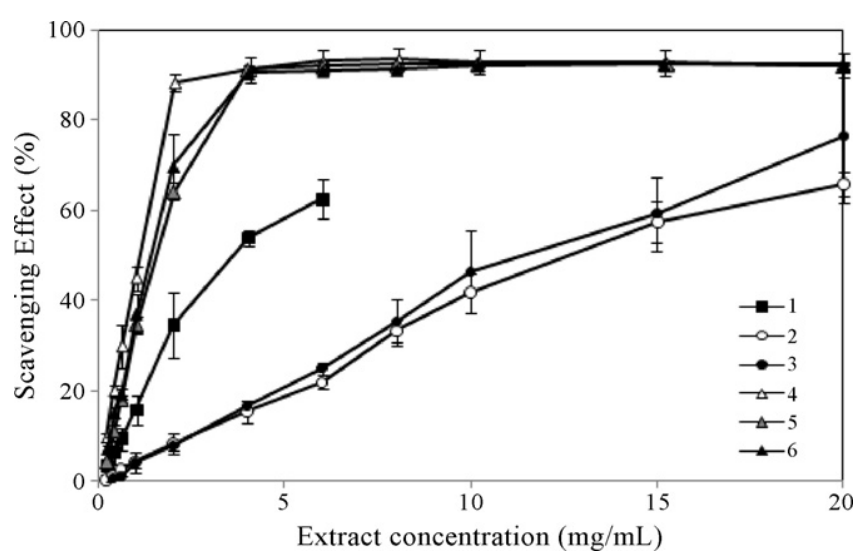

Fig. 2. Scavenging effect of hazelnut kernels extracts obtained by different extraction conditions: (1) boiling water for $45 \mathrm{~min}$; ( 2 and 3) methanol for 24 and $24+24 \mathrm{~h}$ respectively; (4-6) $80 \%(\mathrm{v} / \mathrm{v}$ ) aqueous acetone for $24,24+24$ and $24+24+24 \mathrm{~h}$, respectively. Results are expressed as mean $\pm \operatorname{SD}(n=6)$.

\subsection{Comparisons of the antioxidant activities of different nuts}

Because the highest antioxidant activity, estimated by scavenging activity against DPPH radicals, was obtained with aqueous acetonic extracts $(24 \mathrm{~h})$, this extraction condition was applied to several nuts; namely, walnut, almond, pine nut and peanut (Fig. 3 ).

The highest extraction yield (Fig. 3A) was obtained with hazelnut extracts. No significant differences $(p>0.05)$ were observed between the other nuts (walnut, almond, pine nut and peanut).
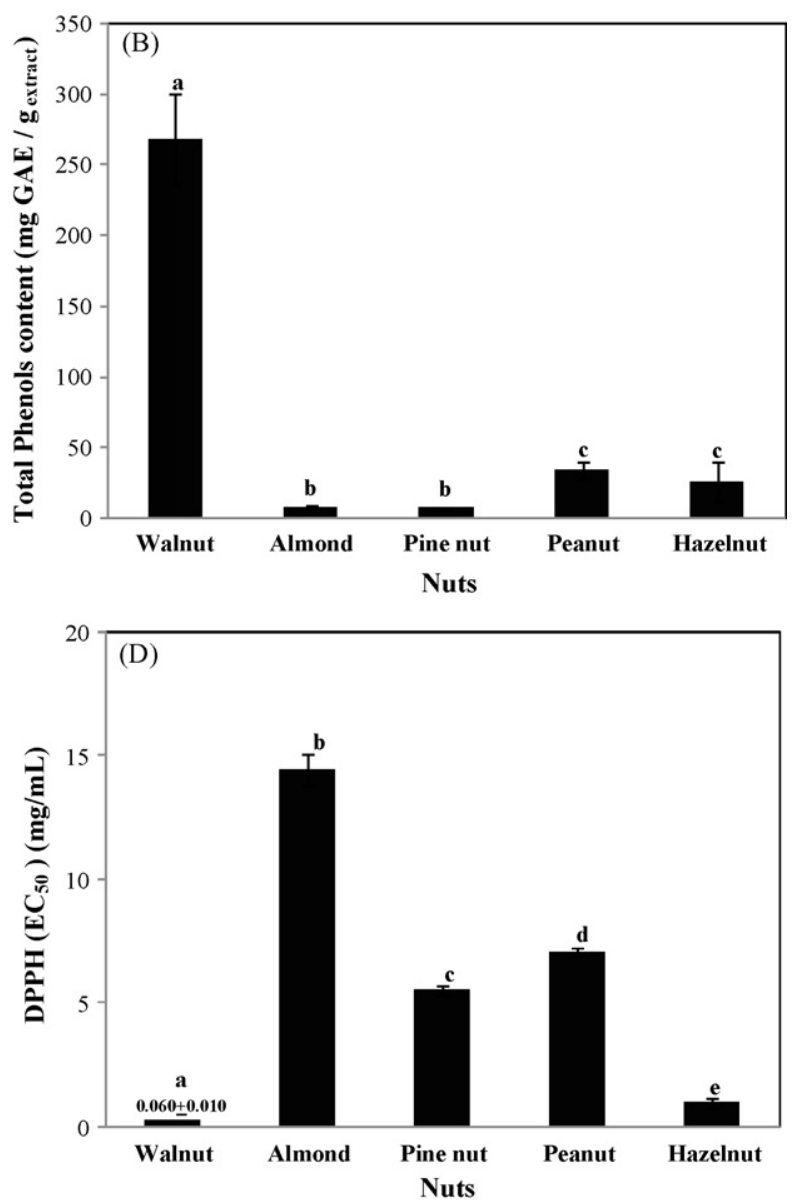

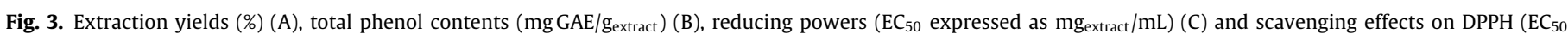
expressed as $\mathrm{mg}_{\text {extract }} / \mathrm{mL}$ ) (D) of tree nuts $80 \%(\mathrm{v} / \mathrm{v})$ aqueous acetonic extracts $(n=6)$. 

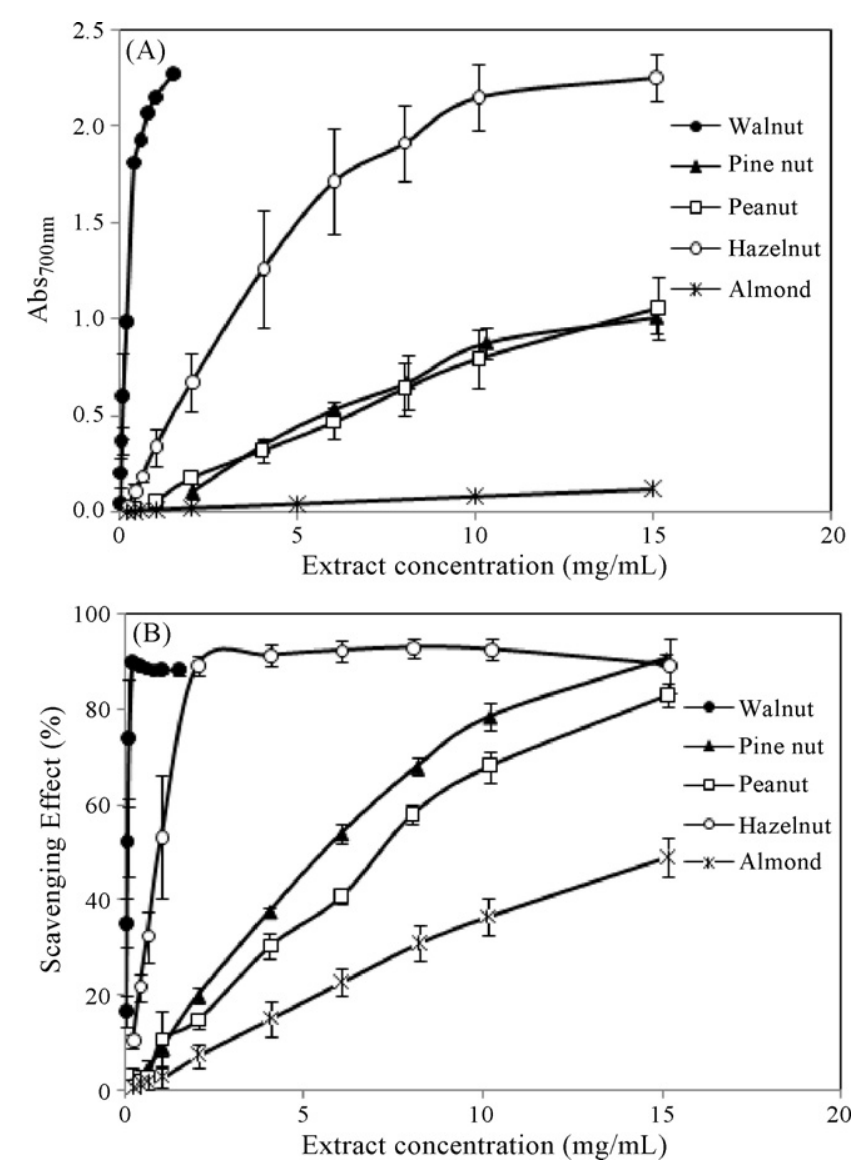

Fig. 4. Reducing powers (A) and scavenging effects on DPPH radicals (\%) (B) of tree nuts $80 \%(\mathrm{v} / \mathrm{v})$ aqueous acetonic extracts $(n=6)$.

The walnut extract was the richest source of total phenols (Fig. 3B). The total phenol contents of hazelnut and walnut acetonic extracts determined in the present study (25.8 and $268 \mathrm{mg} \mathrm{GAE} / \mathrm{g}_{\text {extract}}$, respectively, equivalent to 421 and $1659 \mathrm{mg} \mathrm{GAE} / 100 \mathrm{~g}_{\text {fruit }}$ weight $)$ were comparable to the ranges that Kornsteiner et al. (2006) reported for acetonic hazelnut and walnut extracts (101-433 and $1020-2052 \mathrm{mg}$ of $\mathrm{GAE} / 100 \mathrm{~g}_{\text {fruit }}$ weight, respectively). Pine nuts yielded $6.9 \mathrm{mgGAE} / \mathrm{g}_{\text {extract }}$ or $37 \mathrm{mgGAE} / 100 \mathrm{~g}_{\text {fruit weight, }}$, which was also within the range reported by Kornsteiner et al. (2006) (32 mg GAE/100 $g_{\text {fruit weight }}$ ). Peanuts showed a significantly higher total phenol content $(p<0.05), 33.6 \mathrm{mg} \mathrm{GAE} / \mathrm{g}_{\text {extract }}$ or $248 \mathrm{mg} \mathrm{GAE} / 100 \mathrm{~g}_{\text {fruit weight }}$, than pine nuts. However, these results were lower than those reported by Kornsteiner et al. (2006) for peanuts with skin (326-552 mg GAE/100 g fruit weight $_{\text {). }}$.

Concerning antioxidant activity, the extracts' reducing powers and scavenging effects on DPPH radicals increased when the concentration increased (Fig. 4A and B, respectively). Taking into account the results obtained for both assays (Fig. $3 \mathrm{C}$ and $\mathrm{D}$ ), the ranking of antioxidant capacity of nut kernels was: walnut $>$ hazelnut $>$ pine nut $\geq$ peanut $>$ almond. With almonds, it was not possible to reach an absorbance of 0.5 in the reducing-power assay (Fig. $4 \mathrm{~A}$ ), so no $\mathrm{EC}_{50}$ value could be determined. This means that the compounds extracted from almonds with $80 \%(\mathrm{v} / \mathrm{v})$ aqueous acetone did not display considerable reducing power, probably because of their inability to act as electron donors. In the free radical scavenging assays (Fig. 3D), almonds had the highest $\mathrm{EC}_{50}$ value, which again indicates their low antioxidant activity and their inability to suppress radical chain reactions by converting free radicals to more stable products. It must be taken into account that the almonds analyzed in the present study were skinless, and the brown skin of almonds may be an important source of phenolic compounds. In a previous study, Siriwardhana and Shahidi (2002) obtained the highest phenolic content for brown skin extracts (87.8 mg of catechin equivalents (CE) per gram of extract) when they were compared to extracts from almond seeds ( $8.1 \mathrm{mg}$ of $\mathrm{CE} / \mathrm{g}$ ) and green shells (leafy cover) (71.1 mg of CE/g).

Our results were identical to the ones reported by Arcan and Yemenicioglu (2009), who analyzed hazelnuts, walnuts and pistachios and obtained the highest antioxidant activities for fresh aqueous and ethanolic walnut extracts $(7713 \pm 176$ and $3363 \pm 41 \mu \mathrm{mol}$ trolox equivalents $/ 100 \mathrm{~g}_{\text {dry weight, }}$, respectively).

To determine which nut specie had the highest phenolic content and/or antioxidant activity and therefore the greatest potential for use in new cosmetic and pharmaceutical products, the total phenol contents of one-portion (i.e., $42 \mathrm{~g}$ ) of nuts were compared. This one-portion value was introduced by Arcan and Yemenicioglu (2009) in a similar study that compared nuts with different types of teas (black, Earl Grey and green). Because walnuts had the highest phenol content (around $696 \mathrm{mg} \mathrm{GAE} /$ one-portion), our results indicate that one-portion of walnuts is equivalent to four-portions of hazelnuts, seven-portions of peanuts, 43-portions of almonds and 45 -portions of pine nuts, showing that walnuts, followed by hazelnuts, were the nuts with the greatest potential source of natural antioxidant compounds to incorporate into products for health and well being. However, it must be remembered that the peanuts, almonds and pine nuts used in the present work had their seed coats removed, and the seed coat may be an important source of phenols. Recent studies by Kornsteiner et al. (2006), Arcan and Yemenicioglu (2009) and Alasalvar et al. (2009) clearly show the importance of seed coats to the antioxidant activities of nuts.

\section{Conclusions}

The results of this study clearly showed that the solvent and time of contact used in hazelnut kernel extractions impacted the extracts' total phenol contents and antioxidant activities. Boiling water and $80 \%(\mathrm{v} / \mathrm{v})$ aqueous acetone produced extracts with the highest total phenol contents; methanol was the least efficient solvent. Increasing the contact time did not improve the phenol extraction for extractions performed with aqueous acetone. The acetonic extracts obtained after $24 \mathrm{~h}$ had the highest proportion of DPPH-active phenolic compounds and, therefore, the highest antioxidant activity, indicating that these extraction conditions were efficient for removing phenolic compounds with antioxidant properties from nuts. When these extraction conditions were applied to several other nuts, walnut extracts exhibited the highest phenol content and antioxidant activities as measured by reducing power and free radical scavenging capacity, followed by hazelnut extracts. Finally, this work demonstrated that nuts are a source of bioactive compounds that could be incorporated into new products that promote human health and well being.

\section{References}

Alasalvar, C., Karamac, M., Amarowicz, R., Shahidi, F., 2006. Antioxidant and antiradical activities in extracts of hazelnut kernel (Corylus avellana $\mathrm{L}$.) and hazelnut green leafy cover. J. Agric. Food Chem. 54, 4826-4832.

Alasalvar, C., Karamac, M., Kosinska, A., Rybarczyk, A., Shahidi, F., Amarowicz, R., 2009. Antioxidant activity of hazelnut skin phenolics. J. Agric. Food Chem. 57, 4645-4650.

Arcan, I., Yemenicioglu, A., 2009. Antioxidant activity and phenolic content of fresh and dry nuts with or without the seed coat. J. Food Compos. Anal. 22, 184-188.

Arranz, S., Cert, R., Pérez-Jiménez, J., Cert, A., Saura-Calixto, F., 2008. Comparison between free radical scavenging capacity and oxidative stability of nut oils. Food Chem. 110, 985-990.

Berker, K.I., Güçlü, K., Tor, I., Apak, R., 2007. Comparative evaluation of Fe(III) reducing power-based antioxidant capacity assays in the presence of phenanthroline, batho-phenanthroline, tripyridyltriazine (FRAP), and ferricyanide reagents. Talanta 72, 1157-1165. 
Blomhoff, R., Carlsen, M.H., Andersen, L.F., Jacobs Jr., D.R., 2006. Health benefits of nuts: potential role of antioxidants. Br. J. Nutr. 96 (Suppl. 2), S52-S60.

Contini, M., Baccelloni, S., Massantini, R., Anelli, G., 2008. Extraction of natural antioxidants from hazelnut (Corylus avellana L.) shell and skin wastes by long maceration at room temperature. Food Chem. 110, 659-669.

Durak, I., Köksal, I., Kaçmaz, M., Büyükkoçak, S., Çimen, B.M.Y., Öztürk, H.S., 1999. Hazelnut supplementation enhances plasma antioxidant potential and lowers plasma cholesterol levels. Clin. Chim. Acta 284, 113-115.

Klimczack, I., Malecka, M., Szlachta, M., Gliszczynska-Swiglo, A., 2007. Effect of storage on the content of polyphenols, vitamin $C$ and the antioxidant activity of orange juices. J. Food Compos. Anal. 20, 313-322.

Köksal, A.I., Artik, N., Simsek, A., Günes, N., 2006. Nutrient composition of hazelnut (Corylus avellana L.) varieties cultivated in Turkey. Food Chem. 99, 509-515.

Kornsteiner, M., Wagner, K.H., Elmadfa, I., 2006. Tocopherols and total phenolics in 10 different nut types. Food Chem. 98, 381-387.

Makkar, H.P.S., 2000. Quantification of tannins in tree foliage. A laboratory manual. In: Makkar, H.P.S. (Ed.), FAO/IAEA Working Document, Vienna, Austria.

Miraliakbari, H., Shahidi, F., 2008. Antioxidant activity of minor components of tree nut oils. Food Chem. 111, 421-427.

Oliveira, I., Sousa, A., Sá Morais, J., Ferreira, I.C.F.R., Bento, A., Estevinho, L.M., Pereira, J.A., 2008. Chemical composition, and antioxidant and antimicrobial activities of three hazelnut (Corylus avellana L.) cultivars. Food Chem. Toxicol. 46, 1801-1807.
Orem, A., Balaban, F., Kural, B.V., Orem, C., Turhan, I., 2008. Hazelnut consumption protect low density lipoprotein (LDL) against oxidation and decrease plasma oxidazed LDL level. In: Proceedings of the 77th Congress of the European Atherosclerosis Society, Istanbul, Turkey, p. 215.

Parcerisa, J., Richardson, D.G., Rafecas, M., Codony, R., Boatella, J., 1998. Fatty acid, tocopherol and sterol content of some hazelnut varieties (Corylus avellana $\mathrm{L}$.) harvested in Oregon (USA). J. Chromatogr. A 805, 259-268.

Shahidi, F., Alasalvar, C., Liyana-Pathirana, C.M., 2007. Antioxidant phytochemicals in hazelnut kernel (Corylus avellana L.) and hazelnut byproducts. J. Agric. Food Chem. 55, 1212-1220.

Singleton, V.L., Rossi Jr., J.A., 1965. Colorimetry of total phenolics with phosphomolybdic-phosphotungstic acid reagents. Am. J. Enol. Vitic. 16, 144-158.

Siriwardhana, S.S.K.W., Shahidi, F., 2002. Antiradical activity of extracts of almond and its by-products. J. Am. Oil Chem. Soc. 79, 903-908.

Sousa, A., Ferreira, I.C.F.R., Barros, L., Bento, A., Pereira, J.A., 2008. Effect of solvent and extraction temperatures on the antioxidant potential of traditional stoned table olives “alcaparras". LWT Food Sci. Technol. 41, 739-745.

Venkatachalam, M., Sathe, S.K., 2006. Chemical composition of selected edible nut seeds. J. Agric. Food Chem. 54, 4705-4714. 